\title{
Requests Made by Australian Learners of Chinese as a Foreign Language
}

\author{
Wei Li \\ School of Languages and Cultures, University of Queensland, St. Lucia, Brisbane, QLD 4072, Australia \\ Wenying Jiang \\ School of Languages and Cultures, University of Queensland, St. Lucia, Brisbane, QLD 4072, Australia
}

\begin{abstract}
This study examines how Australian learners of Chinese make requests as compared to those made by native speakers of Mandarin Chinese. Data were collected through a written production questionnaire comprising six situations. Results showed that learners and native speakers shared a preference for conventional indirectness. However, they favoured different strategy types in the realizations of requests. Moreover, native speakers tended to adjust their selection of request strategies according to social variables such as relative power, social distance, and rank of imposition, whereas learners displayed little sensitivity to social variables in the selection of request strategies. This study also provides some evidence of pragmatic development. Learners' use of directness decreased but their use of conventional indirectness increased with increased proficiency. Moreover, learners' acquisition of pragmalinguistic competence seemed to outperform their sociopragmatic competence. This study adds to the small body of research on requests by learners of Chinese as a foreign language. It highlights the importance of the inclusion of pragmatics in foreign language teaching.
\end{abstract}

Index Terms - request, speech act, (in)directness, Chinese, pragmatic development

\section{INTRODUCTION}

Interlanguage pragmatics (ILP) deals with how non-native speakers (NNSs) understand and produce speech acts in a target language (L2), and how their L2-related speech act knowledge is acquired (Kasper \& Dahl, 1991, p. 216). There have been a substantial number of empirical studies which examine L2 learners' production of speech acts. Among all the speech acts studied in ILP, requests, due to their frequent use in daily communication and their highly face-threatening nature, have received the most attention. Despite the large number of studies on interlanguage requests, most of them focus on requestive behavior of learners of English (e.g. Economidou-Kogetsidis, 2008, 2010; Trosborg, 1995; Wang, 2011; Woodfield \& Economidou-Kogetsidis, 2010; Yu, 1999), or learners of other Western languages such as German (Faerch \& Kasper, 1989), Hebrew (Blum-Kulka, 1982), and Spanish (Félix-Brasdefer, 2007). Only a few studies are concerned with requests by learners of Asian languages such as Indonesian (Hassall, 2003) and Korean (Byon, 2004). The range of target languages is relatively small (Bella, 2012; Hassall, 2003). To the best of the researchers' knowledge, little research has been done examining requests made by Australian learners of Chinese.

Previous studies on Chinese requests (Lee-Wong, 1994; Zhang, 1995) and Australian English requests (Blum-Kulka et al., 1989; Wierzbicka, 1985) have suggested that there are considerable differences between Mandarin Chinese and Australian English in the realizations of requests. Moreover, studies of requests by Chinese learners of English as compared with those made by Australian English speakers (Li, 2018; Wang, 2011) have shown that Chinese learners of English often diverge from the target norm in their realizations of requests. It would be interesting to look at how Australian learners of Chinese make requests in L2 Chinese.

The body of research on interlanguage pragmatic performance is large. A long-standing criticism points out that research in ILP focuses mainly on NNSs' pragmatic performance rather than on language learners' pragmatic development (Kasper \& Rose, 2002; Kasper \& Schmidt, 1996). In the last decade, there has been a limited but growing number of studies on L2 pragmatic development (e.g. Achiba, 2003; Barron, 2003; Bella, 2012; Félix-Brasdefer, 2007; Savić, 2015; Woodfield, 2012). More research needs to be conducted to address the relative shortage of developmental studies.

To sum up, the present study attempts to fill in some of the gaps in interlanguage pragmatics. It investigates the requestive behavior of Australian learners of Chinese, a group of learners that have rarely been studied in ILP. To meet the need for developmental research in ILP, it also examines whether learners move towards the target norm in their selection of request strategies as their language proficiency increases.

\section{LitERATURE REVIEW}

A. Definition of Requests 
According to Searle's (1969) classification of illocutionary acts, requests fall into the category of directives. Requests are illocutionary acts whereby a speaker attempts to get the hearer to perform an act which is usually for the benefit of the speaker.

Brown and Levinson (1987) claim that requests are intrinsically face-threatening and by their nature run contrary to the addressee's face want. In attempting to get the interlocutor to do something, the speaker impinges on the interlocutor's freedom of action and thus threatens the interlocutor's negative face. The speaker's positive face is also threatened to a certain extent, because if a request is refused the requester's face want to be approved of may not be satisfied (Barron, 2003; Trosborg, 1995). Therefore, a high level of pragmatic competence is required of L2 learners for the successful completion of requests (Bella, 2012; Byon, 2004).

\section{B. Empirical Studies on Requests}

Among the large number of empirical studies on requests, the most well-known is the Cross-Cultural Speech Act Realization Project (CCSARP) conducted by Blum-Kulka et al. (1989). According to the CCSARP framework, requests consist of head acts and peripheral elements. A head act is the minimal unit to realize a request independently of other elements. It is the core request or request proper. The peripheral elements refer to alerters preceding the head act and supportive moves either preceding or following the head act. The present study only focuses on the request head acts. Head acts vary in levels of directness: directness, conventional indirectness and nonconventional indirectness, which are further divided into nine strategy types or sub-strategies. The findings of the CCSARP indicate that of the eight languages under investigation, Australian English speakers choose conventional indirectness with the highest frequency and are the least direct. Moreover, they show a preference for conventional indirectness in all situations, displaying the lowest degree of situational variation.

The coding framework of the CCSARP has been extensively used and tested and proven to be an effective and reliable coding scheme (e.g., Bella, 2012; Byon, 2004; Hassall, 2003; Rue \& Zhang, 2008; Savić, 2015). It will be adapted to analyze the request data in the present study.

Empirical studies which focus on the production of L2 requests abound. Most of these studies are concerned with requests made by learners of English or other European languages. For example, Trosborg (1995) examines the requestive behavior of Danish learners of English at three proficiency levels: low, intermediate and advanced. Faerch and Kasper (1989) look at how Danish learners of English and German perform requests in different target languages. Economidou-Kogetsidis (2008) and Woodfield and Economidou-Kogetsidis (2010) compare requests by Greek learners of English with those by British English speakers. Only a few studies have been conducted to investigate requests by learners of Asian languages, among which Hassall (2003) examines how Australian learners of Indonesian make requests as compared to Indonesian native speakers, and Byon (2004) compares requests made by American learners of Korean with those of Korean speakers and American English speakers.

Findings of these studies indicate that learners often deviate from native speakers (NSs) in their realizations of requests, which can be attributed to several factors. One of the important factors is negative pragmatic transfer, which occurs where pragmatic features in L1 differ from those in L2 but learners transport these features from L1 to L2 (Kasper, 1992; Maeshiba et al., 1996). Negative transfer has great potential for pragmatic failure, which is "an important source of cross-cultural communication breakdown" (Thomas, 1983, p. 97). L2 learners' pragmatic transfer in requests has been reported in a number of studies (e.g. Blum-Kulka, 1982; Byon, 2004; Economidou-Kogetsidis, 2008; Faerch \& Kasper, 1989; Li, 2018).

Another important factor responsible for L2 learners' deviations relates to teaching induction. A good example of teaching-induced errors is found in Hassall's (2003) study of requests by Australian learners of Indonesian. Hassall observes that Australian learners display an overwhelming preference for boleh [may] over bisa [can] to perform Query preparatory requests, in contrast with Indonesian NSs who strongly favor bisa. He attributes this to the instruction that the learners had in the use of these two modal verbs. Hassall argues that in the learners' textbook boleh is invariably used to ask for permission, whereas bisa is presented and practiced only with reference to ability. Thus, the two modal verbs are implicitly contrasted in a way that seems to suggest that bisa is not used to ask for permission (Hassall, 2003, p.1919).

As noted above, the body of research on interlanguage pragmatic performance is large; however, the same cannot be said of studies on ILP development, although there have been a growing number of developmental studies in recent years. Longitudinal request studies by Ellis (1992) and Achiba (2003) reveal that over time learners' use of direct request strategies decreases, whereas their use of conventionally indirect strategies increases. These developmental trends are supported by the findings of cross-sectional studies (e.g. Bella, 2012; Félix-Brasdefer, 2007; Rose, 2000, 2009) which show that direct strategies decrease while conventionally indirect strategies increase with increased proficiency.

Regarding the development of pragmalinguistic vs. sociopragmatic competence, studies of L2 pragmatics have yielded inconclusive results. Some studies point to the precedence of pragmalinguistics over sociopragmatics. For example, Scarcella and Brunak (1981), one of the earliest studies on L2 pragmatic development, find that despite already possessing universal pragmatic knowledge, Arabic learners of English are unable to vary their selection of politeness strategies, such as indirectness, according to the social status of the addressee. Barron (2003), in a longitudinal study of the pragmatic development of Irish learners of German over a ten-month period in Germany, 
reports that despite a relatively advanced level of pragmalinguistic competence, learners' sociopragmatic competence lags somewhat behind. Moreover, Rose (2000, 2009), in two cross-sectional studies which examine pragmatic development of young Chinese EFL learners in Hong Kong, finds evidence of pragmalinguistic development in both studies, particularly in the movement from direct to conventionally indirect strategies; however, there is little evidence of sociopragmatic development in either study given the lack of situational variation in request strategies across the groups. Additionally, Savić (2015) investigates the pragmatic development of requests by young Norwegian EFL learners. Her results show clear pragmalinguistic development but little evidence of sociopragmatic development.

By contrast, Bardovi-Harlig and Hartford's (1993) longitudinal study of L2 pragmatic development indicates that L2 learners' acquisition of sociopragmatic competence outperforms that of pragmalinguistic competence. Their study shows that over time NNSs learn to choose more appropriate speech acts, which indicates their development in sociopragmatic competence. However, they change little in their ability to employ appropriate forms of the speech acts, which suggests little development in pragmalinguistic competence. Bardovi-Harlig and Hartford's findings were supported by Bardovi-Harlig and Griffin (2005) and Schmidt (1983).

\section{Studies on Requests by Chinese Speakers}

Although a large number of studies have been conducted to investigate requests in a variety of languages and cultures, only a few have been done to examine requests by Chinese native speakers, and the literature reveals discrepancies among the findings.

Lee-Wong's (1994) study is among the earliest on L1 Chinese requests. Using interviews and a 30-item written questionnaire as the data collection methods, Lee-Wong examines requests made by Chinese NSs from mainland China. The findings reveal an overwhelming preference for direct strategies, with Mood derivable in the form of imperatives as the predominant strategy type. Conventionally indirect requests come far behind as the second main strategy, followed by nonconventionally indirect strategies. However, Zhang's (1995) study of Chinese request strategies via a 12-situation questionnaire conflicts with Lee-Wong's. Zhang finds that Chinese requests share a preference for conventional indirectness with the languages investigated by the CCSARP (Blum-Kulka et al. 1989). Conventional indirectness is the most preferred main strategy with Query preparatory being the most common sub-strategy, followed by directness and nonconventional indirectness.

Moreover, a number of studies examine requests by Chinese learners of English. For example, Yu (1999) compares requests made by Taiwanese ESL learners with those by American English speakers and Taiwanese Chinese speakers. Wang (2011) examines requestive behavior of Chinese EFL learners in Macau, as compared with Australian English speakers. A recent study by Li (2018), which focuses on pragmatic transfer, compares email requests made by Chinese EFL learners in mainland China with those made by NSs of Mandarin Chinese and Australian English. The findings of these studies indicate that Chinese learners of English select direct strategies more often but conventionally indirect strategies less often than English NSs. Moreover, in both Yu and Li's studies, Chinese NSs used direct strategies significantly more often but conventionally indirect strategies significantly less often than English NSs.

\section{Studies on Requests by Learners of Chinese}

Studies on requests by learners of Chinese as a foreign language (CFL) remain under-researched (Taguchi, 2015). To the researchers' best knowledge, only a few studies have been undertaken to examine requests made by learners of Chinese, among which Hong (1997) compares request strategies by heritage and non-heritage learners of Chinese, Li (2012) investigates the effects of input-based practice on the pragmatic development of requests in L2 Chinese, and Zhang and Yu (2008) and Li (2014) examine the pragmatic development of learners of Chinese in requests in a study abroad context.

A study conducted by Wen (2014) is more relevant to the present study. Using a four-scenario written questionnaire, Wen investigates the pragmatic development by American learners of Chinese in requests. Two groups of learners at lower and higher proficiency levels and one group of Chinese NSs participated in the study. Her findings reveal consistent evidence of pragmalinguistic development. For example, learners' use of conventional indirectness increases and their use of directness decreases as their language proficiency improves. Also, like NSs, both learner groups predominantly rely on the conventionally indirect strategy type Query preparatory. Further evidence of pragmalinguistic development is found in the learners' increased use of Hedged performative with increased proficiency. Moreover, Wen's study also reveals evidence of sociopragmatic development, which is seen in the higher proficiency learners' sensitivity to situational variation in their selection of downgraders and supportive moves.

In summary, the literature has indicated that although requests are the most often studied speech act in interlanguage pragmatics, the range of target languages is rather small. Studies on requests by learners of Chinese have lagged far behind those by learners of English. Moreover, despite the growing number of developmental studies, more work needs to be conducted.

The present study attempts to answer the following questions:

(1) To what extent do Australian learners of Chinese differ from Chinese native speakers in directness levels and strategy types in making requests?

(2) To what extent do Australian learners of Chinese differ from Chinese native speakers in situational variation in the selection of directness levels and strategy types. 
(3) Is there any evidence of pragmatic development in Australian learners' performance of requests in L2 Chinese?

\section{METHOD}

\section{A. Instruments}

The main data elicitation method for the present study was a discourse completion test (DCT). Informal interviews were used to aid the interpretation of the data.

DCTs were first used by Blum-Kulka (1982) to examine the requestive behavior of English learners of Hebrew and then adopted by Blum-Kulka et al. (1989) for the well-known cross-cultural speech act project. Since then they have been extensively used as the data collection method in ILP. Despite being the most commonly used method in ILP, DCTs have evidenced drawbacks, which have been widely discussed. For example, DCTs have been criticized for eliciting oral data using a written mode (e.g. Hinkel, 1997; Sasaki, 1998). The DCT data do not have the number of turns, the length of responses, the emotional depth, or other features of natural conversation (Bardovi-Harlig, 2013; Beebe \& Cummings, 1996). However, DCTs have incomparable advantages. Apart from gathering a large amount of data quickly and allowing full control of contextual variables, DCTs 'provide useful information about speakers' pragmalinguistic knowledge of the strategies and linguistic forms by which communicative acts can be implemented, and about their sociopragmatic knowledge of the context factors under which particular strategies and linguistic choices are appropriate" (Kasper \& Rose, 2002, p.96).

The DCT was selected as the data elicitation method for the present study because it fits well the purpose of this study. The present DCT was part of a placement test to screen second-year students learning Chinese as a foreign language in Australia. It was developed to assess students' grammatical and pragmatic knowledge of the linguistic means and forms covered in the textbook.

The original DCT comprised ten situations. Six of them are requests, which are the focus of the present study. For the sake of realism, all the situations were designed to resemble those that take place in an academic setting with which the participants were familiar. The request situations vary according to social distance (D), relative power (P), and rank of imposition (R), the three social variables which commonly influence people's selection of linguistic strategies and forms in requests (Brown \& Levinson, 1987).

The DCT questionnaire used to elicit the data from the Chinese baseline group was written in Chinese. The DCT used to elicit the Australian CFL data was originally in Chinese. However, the findings of a pilot study showed that most CFL learners had difficulty understanding what the situations in the DCT were about. Given the low proficiency level of the Australian CFL learners in this study, the questionnaire used to elicit the Australian data was translated into English, with potentially unfamiliar vocabulary and expressions given in Chinese in the brackets. Situational descriptions for the CFL group are provided in the Appendix.

Furthermore, a perception questionnaire was developed to investigate the politeness and appropriateness of the Australian CFL learners' requests. The questionnaire consists of three direct strategies and three indirect strategies selected from the learner data in the reference situation. Native speaker participants were asked to rate the (in)appropriateness of the requests on a 5-point Likert scale and provide explanations.

\section{B. Participants}

Twenty Australian learners of Chinese and 20 Mandarin Chinese speakers took part in this study. The Australian participants were second-year students majoring in Chinese as a foreign language at a university in Brisbane, Australia. They were all from an Anglo-European cultural background. They had learned Chinese for an average of 1.5 years. Twelve of them were female and eight were male. Their average age was 20 . The CFL learners were further divided into two groups based on their end-of-semester academic results. The low proficiency group was made up of nine students whose results were Grade 5 or below. The high proficiency group included 11 students whose results were Grades 6 and 7 (with 7 being the highest grade and 4 being the lowest pass grade at the university).

The participants in the Chinese baseline group were undergraduate and postgraduate students who majored in economics and finance at a university in Jinan, China. They were all NSs of Mandarin Chinese (MCs). Eleven of them were female and nine were male. Their average age was around 23.

Moreover, ten NSs of Mandarin Chinese who were university lecturers, researchers and journalists in Australia and China were asked to rate the (in)appropriateness of the selected requests on a 5-point Likert scale and provide reasons for their choice. Four of them were female and six were male. Their ages ranged between 35 and 52.

\section{Data Collection Procedure}

Data collection with the Australian CFL group took place in July, 2017. One of the instructors distributed the paper questionnaires to the students in class. Students were asked to write down in either pinyin or characters what they would really say if they had come across such situations in real life. The whole data collection took about 30 minutes.

The Chinese baseline data were collected via WeChat, the most popular social media app in China, in October, 2017. An electronic version of the questionnaire was sent to a colleague at a university in China, who assisted in recruiting Chinese participants, and distributing and collecting the questionnaires. The colleague sent completed questionnaires to the first researcher via WeChat. 
The perception data were collected via WeChat in November, 2017. An electronic version of the questionnaire was sent to the participants, who were asked to complete the survey either on a computer or a smart phone and then sent the completed questionnaire back to the researchers through WeChat.

\section{Data Analysis}

The present study focuses on directness levels and strategy types used in the request head act. The data classification method was adapted from the coding schemes developed by Blum-Kulka et al. (1989), Hassall (2003) and Zhang (1995). Directness levels and strategy types within each level of directness that occurred in this study are outlined and exemplified below.

1. Directness

(1) Mood derivable. The grammatical mood of the locution marks its illocutionary force as a request. The prototypical form is imperative, e.g. 请帮我! [Please help me!]

(2) Explicit performative. The illocutionary force of the utterance is named explicitly with a relevant performative verb, such as 请 [please], 请求 [please ask], and 麻烦 [trouble] in Chinese, e.g. 恳请老师帮我写一封推荐信 [I earnestly ask the teacher to do me the favor of writing me a reference].

(3) Hedged performative. The illocutionary verb denoting the requestive intent is modified by modal verbs such as can, must, and have to, e.g. 可以请老师帮我写吗? [May I please ask the teacher to write me (a reference)?]

(4) Want/need statement. The speaker states desire, wish or need that the event denoted in the proposition come about, e.g. 希望得到老师的批准 [Hope that I can have the teacher's approval.]

2. Conventional indirectness

(5) Query preparatory: ability. The speaker asks about the hearer's ability to perform the act, or the possibility of the act to be performed, e.g. 能不能借你的笔记看一下? [Can I borrow your notes?]

(6) Query Preparatory: permission. The speaker asks the hearer for permission to perform the act, e.g. 我可不可以 采访你? [May I interview you?]

(7) Query Preparatory: availability. The speaker asks about the availability or convenience of the hearer performing the act, e.g. 不知您是否方便帮我写一下? [Just wondering if it is convenient for you to write me (a reference)?]

3. Nonconventional indirectness (hints). The illocutionary intent is not immediately derivable from the utterance. Unlike conventionally indirect strategies, hints are not conventionalized and require more inference on the part of the requestee, e.g. 我还有机会选这门课吗? [Have I got any chance to select this course?]

The data were coded by the two authors. As a narrow range of strategies was employed by the participants, the inter-rater reliability was approximately 95\%. All discrepancies were discussed and a consensus was reached. Both qualitative and quantitative methods were used to analyze the data. The chi-square test was employed to determine the statistical significance of the differences between the Australian group and the Chinese group in the overall frequencies of directness levels and strategy types.

\section{RESULTS}

\section{A. Levels of Directness}

TABLE 1.

OVERALL FREQUENCY OF DIRECTNESS LEVELS AND STRATEGY TYPES BY CFLS AND MCS

\begin{tabular}{lllll}
\hline & CFL & \multicolumn{3}{c}{ MC } \\
\cline { 2 - 5 } Directness levels and strategy types & n. & $\%$ & n. & $\%$ \\
\hline Directness & $\mathbf{2 1}$ & $\mathbf{1 7 . 5}$ & $\mathbf{2 9}$ & $\mathbf{2 4 . 2}$ \\
Mood derivable & 15 & 12.5 & 4 & 3.3 \\
Explicit performative & 5 & 4.2 & 2 & 1.7 \\
Hedged performative & 0 & 0.0 & 13 & 10.8 \\
Want statement & 1 & 0.8 & 10 & 8.3 \\
Conventional indirectness & $\mathbf{9 0}$ & $\mathbf{7 5}$ & $\mathbf{8 8}$ & $\mathbf{7 3 . 3}$ \\
Preparatory: ability & 17 & 14.2 & 50 & 41.7 \\
Preparatory: permission & 73 & 60.8 & 25 & 20.8 \\
Preparatory: availability & 0 & 0.0 & 13 & 10.8 \\
Non-conventional indirectness (hint) & $\mathbf{9}$ & $\mathbf{7 . 5}$ & $\mathbf{3}$ & $\mathbf{2 . 5}$ \\
\hline
\end{tabular}

Table 1 presents the frequency of directness levels and strategy types within each level of directness by the Australian CFL learners and Mandarin Chinese speakers. The CEL group shared a preference for conventional indirectness with the MCs. Both groups used conventional indirectness the most frequently, followed by directness and non-conventional indirectness. While the two groups employed conventional indirectness with a similar frequency, learners chose directness less often but nonconventional indirectness more often than native speakers. Nonetheless, Chi-square test results revealed no statistically significant differences between the two groups in the frequency of directness $\left(\chi^{2}=1.617, d f=1, p=.204\right)$ and nonconventional indirectness $\left(\chi^{2}=3.158, d f=1, p=.076\right)$. 
TABLE 2.

FREQUENCY OF DIRECTNESS LEVELS AND STRATEGY TYPES BY LOW AND HIGH GROUPS

\begin{tabular}{lllll}
\hline Directness levels and strategy types & Low & \multicolumn{3}{c}{ High } \\
\cline { 2 - 5 } & $\mathrm{n}$. & $\%$ & $\mathrm{n}$. & $\%$ \\
\hline Directness & $\mathbf{1 7}$ & $\mathbf{3 1 . 5}$ & $\mathbf{4}$ & $\mathbf{6 . 1}$ \\
Mood derivable & 14 & 25.9 & 1 & 1.5 \\
Explicit performative & 3 & 5.6 & 2 & 3.0 \\
Hedged performative & 0 & 0.0 & 0 & 0.0 \\
Want statement & 0 & 0.0 & 1 & 1.5 \\
Conventional indirectness & $\mathbf{3 0}$ & $\mathbf{5 5 . 6}$ & $\mathbf{6 0}$ & $\mathbf{9 0 . 9}$ \\
Preparatory: ability & 7 & 13.0 & 10 & 15.2 \\
Preparatory: permission & 23 & 42.6 & 50 & 75.8 \\
Preparatory: availability & 0 & 0.0 & 0 & 0.0 \\
Nonconventional indirectness(hint) & $\mathbf{6}$ & $\mathbf{1 1 . 1}$ & $\mathbf{3}$ & $\mathbf{4 . 5}$ \\
\hline
\end{tabular}

A closer examination of the directness levels used by the two learner groups in Table 2 indicated that the low group used directness $(31.5 \%)$ more often but conventional indirectness $(55.6 \%)$ considerably less often than the MCs $(24.2 \%$ and $73.3 \%$ respectively). The high group, on the other hand, underused directness $(6.1 \%)$ but overused conventional indirectness $(90.9 \%)$. With regard to nonconventional indirectness, while the high group (4.5\%) used it with a similar frequency to the MCs (2.5\%), the low group overused it and included it in $11.1 \%$ of their requests.

\section{B. Strategy Types}

\section{Direct Strategies}

The strategy types within the level of directness include Mood derivable, Explicit performative, Hedged performative, and Want statements. Chi-square test results revealed statistically significant differences between the CFL group and the Chinese group in Mood derivable $\left(\chi^{2}=6.916, d f=1, p=.009\right)$, Hedged performative $\left(\chi^{2}=13.744, d f=1, p=.000\right)$ and Want statements $\left(\chi^{2}=7.717, d f=1, p=.005\right)$.

Table 1 shows that Mood derivable was used significantly more often by the CFL group (12.5\%) than the Chinese group (3.3\%). A closer inspection of the learner data in Table 2 indicated that it was actually the low group (25.9\%) that overused this direct strategy. The high group (1.5\%) chose it with a frequency similar to that of the MCs. Below are examples of Mood derivable used by the low proficiency learners:

(1) 请 给 我 笔。(Pen)

q̌ing gěi wǒ b̌

[please give me a pen]

Furthermore, it was found that Mood derivable was included in the learners' requests in every situation, whereas it was only employed by the MCs in the notes and pen situations. Also, the MCs always put a tag question after this direct strategy, which was observed in none of the learners' requests. Below is an example of Mood derivable used by a Mandarin speaker when asking a peer to lend notes:

(2) 把 你的笔记 借 我 看一下, 好 吗? (Notes)

bă nĭ de bǐjì jiè wǒ kàn yíxià, hăo ma?

[Lend me your notes for a look, is it OK?]

While learners favored Mood derivable, NSs preferred Hedged performatives (Example 3 below), which were absent in the learners' requests, and Want statements (Example 4), which were only used by one high proficiency learner. Below are examples of these two strategy types by the MCs.

(3) 能 麻烦 老师下次 来上课 的 时候 把 练习 带 给 我 吗? (Handout)

néng máfan lăoshī xià cì lái shàngkè de shíhòu bă liànxí dài gěi wǒ ma?

[Can I trouble the teacher to bring the handout to the next lecture for me?]

(4) 希望 得到 您 的 批准。(Course)

xīwàng dédào nín de pīzhǔn

[I hope I can have your approval.]

\section{Conventionally Indirect Strategies}

Despite a preference for conventional indirectness by both learners and native speakers, there were marked differences between the two groups in the strategy types used. Learners strongly favored Query preparatory: permission, which is usually in the form of kěyl [may]. Chi-square test results revealed a statistically significant difference between the CFL group (60.8\%) and the MCs $(20.8 \%)$ in the use of this sub-strategy, $\chi^{2}=38.221, d f=1, p=.000$.

Examination of the learner data in Table 2 indicates that both low proficiency learners $(42.6 \%)$ and high proficiency learners $(75.8 \%)$ overused the permission strategy; the latter employed it significantly more often than the former. Below are examples of this strategy type by the high group:

(5) 我 可以 借 你 的 笔 吗? (Pen)

wǒ kěyl jiè nĭ de b̌ ma?

[May I borrow your pen?]

(6) 我 可不可以 采访 你? (Interview) 
wǒ kě bu kěy̆ căifăng nĭ?

[May I interview you?]

While learners favored the permission expression kěyı [may], NSs (41.7\%) preferred to ask the hearer's ability or the possibility of performing the requested act, using the modal verb néng [can]. They chose this strategy type significantly more often than the CFL group $(14.2 \%), \chi^{2}=19.547, d f=1, p=.000$. Below are typical examples of Query preparatory used by the MCs:

(7) 能 借 支笔 用 一下 吗? (Pen)

néng jiè zhī bì yòng yí xià ma?

[Can I use your pen for a second?]

(8) 我 能不能 采访 你一下? (Interview)

wǒ néng bu néng căifăng nǐ yíxià?

[Can I interview you for a little while?]

An inspection of the learner data indicated that both the low group (13\%) and the high group (15.2\%) underused the ability strategy.

Apart from asking the hearer about his/her ability or permission, the MCs also checked the availability of the hearer. In contrast, none of the CFL learners employed this strategy type to mitigate the impositive force of their requests. Below is an example from the MCs in the reference situation.

(9) 不知 老师 是否有 时间 在 百 忙 之中 给 我 写封 推荐信。

bù zhī lăoshī shifǒu yǒu shíjiān zài băimáng zhī zhōng gěi wǒ xiě fêng tuījiànxìn

[I wonder if the teacher can find time in your busy schedule to write me a reference letter.]

\section{Nonconventionally Indirect Strategies}

Hints were used the least frequently by either learners or native speakers. However, the data revealed that low proficiency learners $(11.1 \%)$ employed hints more often than either NSs $(2.5 \%)$ or high proficiency learners $(4.5 \%)$. The following are examples of hints used by the low proficiency group.

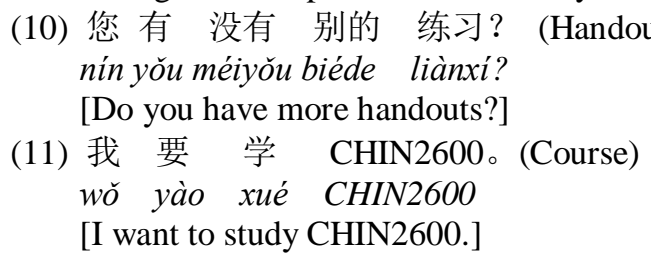

\section{Social Variables}

The findings indicated that social variables did not seem to affect Australian learners at low or high proficiency levels in the selection of directness levels and strategy types as much as they did native speakers. Table 3 presents the frequency of directness levels and strategy types used by learners and native speakers in each situation.

TABLE 3.

FREQUENCY OF DIRECTNESS LEVELS AND STRATEGY TYPES BY CFLS AND MCS IN EACH SITUATION

\begin{tabular}{|c|c|c|c|c|c|c|c|c|c|c|c|c|}
\hline \multirow{2}{*}{$\begin{array}{l}\text { Directness levels } \\
\text { and strategy types }\end{array}$} & \multicolumn{2}{|c|}{ Reference } & \multicolumn{2}{|l|}{ Notes } & \multicolumn{2}{|c|}{ Handout } & \multicolumn{2}{|c|}{ Interview } & \multicolumn{2}{|c|}{ Course } & \multicolumn{2}{|l|}{ Pen } \\
\hline & CFL & $\mathrm{MC}$ & CFL & $\mathrm{MC}$ & CFL & $\mathrm{MC}$ & CFL & $\mathrm{MC}$ & CFL & $\mathrm{MC}$ & CFL & $\mathrm{MC}$ \\
\hline Directness & 40.0 & 40.0 & 15.0 & 15.0 & 10.0 & 30.0 & 10.0 & 5.0 & 10.0 & 45.0 & 15.0 & 10.0 \\
\hline Mood derivable & 20.0 & 0.0 & 15.0 & 10.0 & 5.0 & 0.0 & 5.0 & 0.0 & 10.0 & 0.0 & 15.0 & 10.0 \\
\hline Explicit performative & 20.0 & 5.0 & 0.0 & 0.0 & 5.0 & 5.0 & 0.0 & 0.0 & 0.0 & 0.0 & 0.0 & 0.0 \\
\hline Hedged performative & 0.0 & 25.0 & 0.0 & 0.0 & 0.0 & 25.0 & 0.0 & 0.0 & 0.0 & 15.0 & 0.0 & 0.0 \\
\hline Want statement & 0.0 & 10.0 & 0.0 & 5.0 & 0.0 & 0.0 & 5.0 & 5.0 & 0.0 & 30.0 & 0.0 & 0.0 \\
\hline Conventional indirectness & 60.0 & 60.0 & 85.0 & 85.0 & 85.0 & 70.0 & 90.0 & 90.0 & 50.0 & 45.0 & 85.0 & 90.0 \\
\hline Preparatory: ability & 20.0 & 20.0 & 15.0 & 65.0 & 15.0 & 40.0 & 15.0 & 50.0 & 15.0 & 5.0 & 15.0 & 70.0 \\
\hline Preparatory: permission & 40.0 & 10.0 & 70.0 & 20.0 & 70.0 & 25.0 & 75.0 & 15.0 & 35.0 & 40.0 & 70.0 & 15.0 \\
\hline Preparatory: availability & 0.0 & 30.0 & 0.0 & 0.0 & 0.0 & 5.0 & 0.0 & 25.0 & 0.0 & 0.0 & 0.0 & 5.0 \\
\hline Nonconventional indirectness & 0.0 & 0.0 & 0.0 & 0.0 & 5.0 & 0.0 & $\mathbf{0 . 0}$ & 5.0 & 40.0 & 10.0 & 0.0 & $\mathbf{0 . 0}$ \\
\hline
\end{tabular}

Mandarin speakers tended to adjust their selection of request strategies according to the relative power of the speaker with respect to the hearer, social distance between them, and rank of imposition involved in a request. They chose directness $\left(\chi^{2}=13.141, d f=1, p=.000\right)$ and the strategy types: Hedged performative $\left(\chi^{2}=14.579, d f=1, p=.000\right)$ and Want statements $\left(\chi^{2}=3.927, d f=1, p=.048\right)$ significantly more often in hearer-dominant situations (reference, handout and course) than in equal situations (notes, interview and pen). Similarly, they used Want statements significantly more often when making big requests (reference, interview and course) than small requests (notes, handout, and pen), $\chi^{2}=$ 6.982, $d f=1, p=.008$. They also selected Want Statements considerably more often when making a request in the +distance situations (course and pen) than in the -distance situations (reference, notes, handout and interview), although the difference was only marginally significant, $\chi^{2}=3.491, d f=1, p=.062$. In contrast, learners chose directness with a similar frequency in all the situations except the reference situation, in which they used directness with a frequency $(40 \%)$ higher than in the other situations. Further examination of the strategy types within directness in the reference situation revealed that learners differed markedly from the MCs in that they only used Mood derivable and Explicit 
performative, which were rarely selected by the MCs, who strongly favoured Hedged performative and Want statements.

No striking differences were observed between the two groups in the frequency of conventional indirectness with respect to situational variation. However, an examination of the strategy types indicated that the two groups differed in the selection of Query preparatory: permission, the most preferred strategy type for learners. The MCs chose the permission strategy most frequently in the $+\mathrm{P},+\mathrm{D}$ and $+\mathrm{R}$ situation (i.e. course), where the overall threat to face is perceived as the highest. In contrast, learners chose this strategy the least frequently in this situation. In general, learners chose permission expressions considerably more often in $=P$ than $+P$ situations, $-\mathrm{R}$ than $+\mathrm{R}$ situations, and $-\mathrm{D}$ than $+\mathrm{D}$ situations, whereas the MCs displayed an opposite tendency.

With regard to nonconventional indirectness, there was little difference between Australian learners and Mandarin speakers in terms of situational variation. Both chose hints mainly in the course situation where $\mathrm{P}, \mathrm{D}$, and R are high .

\section{Appropriateness of Learners' Requests}

A perception questionnaire was used to examine the politeness and appropriateness of requests selected from the learner data. Ten Mandarin speakers were asked to rate the (in)appropriateness of the requests on a 5-point Likert scale and provide an explanation for their choice. Results indicated that all participants rated the use of imperatives such as 请给我推荐信 [Please give me a reference letter] and 你写一个推荐信 [You write a reference letter] as either inappropriate or very inappropriate and rude. The following comments on learners' use of imperatives were taken from the perception data.

- ‘请给我推荐信” 很不得体。忽视了双方是师生的关系。有命令的口吻......

['Please give me a reference letter' is very inappropriate. It ignores the hierarchical teacher-student relationship. It sounds like an order.]

- ‘你写一个推荐信”- 这是命令, 不是请求。这个像是将军对士兵下命令, 既然是命令, ‘谢谢” 就显得多余 和虚伪了。

['You write a reference letter' - this is a command, not a request. It sounds like a command from a general to a soldier. Since it is an order, the expression 'Thanks' after it sounds redundant and hypocritical.]

Moreover, most of the participants perceived 你写不写推荐信? [Do you write a reference letter or not?] which omits modal verbs such as 可以 [may] and 能 [can] as either inappropriate or very inappropriate.

- 太突兀，这是威胁，根本不是请求......

[Too abrupt. This is a threat, not a request at all...]

- 很不得体。“你写不写” 然后问号结尾的语句汉语中有威胁的意味。

[Very inappropriate. 'You write or not' followed by a question mark at the end of the sentence has the implication of a threat in Chinese.]

\section{DISCUSSION}

\section{A. Direct Strategies}

With regard to direct strategies, the findings of the study indicated that learners used Mood derivable, the prototypical form of which is the imperative, significantly more often than Chinese NSs. Apparently L1 pragmatic transfer cannot account for the overuse of this direct sub-strategy. Previous studies (Blum-Kulka et al, 1989; Hassall, 2003; Li, 2018; Wierzbicka, 1985) have provided ample evidence that Australian English speakers strongly disfavour direct strategies such as imperatives. A closer inspection of the data reveals that Mood derivable was mainly employed by low proficiency learners. While one fourth of the low group chose Mood derivable as the request head act, only one high proficiency learner did so. This finding corroborates the observations of developmental studies (Achiba, 2003; Ellis, 1992; Felix-Brasdefer, 2007; Rose, 2000), according to which learners rely heavily on imperatives, which are formally simple, in the early stages of pragmatic development. As learners' language proficiency increases, their selection of directness decreases.

Moreover, this study revealed that learners underused Hedged performative and Want statements, which were the predominant direct strategies for the MCs but were only observed in one learner's request. Chinese NSs' preference for these two strategy types has been reported by Yu (1999), Wen (2014) and Li (2018). These strategies sound soft and polite in Chinese, particularly when used with syntactic and lexical downgraders, but are direct and inappropriate in English. Australian learners' underuse of these two direct strategies, therefore, could be attributed to negative pragmatic transfer.

\section{B. Conventionally Indirect Strategies}

The present findings indicated that conventional indirectness was the most preferred strategy for both CFL learners and MCs. However, the data showed that there were marked differences between the two groups in the preferences for strategy types. Learners, particularly the high proficiency learners, strongly favoured the permission strategy and used the modal verb kěyl [may] in most of their requests. While both kěy̆ [may]and néng [can] can be employed to make requests, the MCs were inclined to use the ability strategy néng [can]. Wen (2014) also observes that American learners 
of Chinese in her study tended to use the modal verb kěy in instead of néng. Interestingly, the literature has shown that Can I/you is conventionally used to make requests in English (Blum-Kulka et al, 1989; Hassall, 2003) and Australian English NSs seldom use permission expressions May I/you (Li, 2018). Therefore, pragmatic transfer was not a relevant factor for Australian learners' overuse of permission expressions. An important cause may be the influence of instruction. Hassall (2003), in his study of requests made by Australian learners of Indonesian, finds a strong preference by learners for boleh [may] instead of bisa [can] in query preparatory requests. He explains that learners' overuse of boleh may be attributed to teaching induction, that is, the way that these two modal verbs are presented and practiced may have caused learners of Indonesian to form the deviant rule that bisa is not used to make requests (Hassall, 2003:1919). This may also be the case for the present Australian learners of Chinese. In the textbook that the CFL learners used (Contemporary Chinese edited by Wu, 2015), both kěyı̌ (four times) and néng (three times), which are used to make requests, have occurred in the lessons covered before the conduction of the survey. However, while kěyı̌ is always used to give or ask for permission, néng is often presented and practiced with reference to ability, e.g. 你能不 能吃辣的? [Can you eat hot food?] in Lesson 5. Moreover, a distinction is also made between néng and huì which means the ability acquired through learning. Thus, the importance of néng used to indicate ability rather than asking for permission in a request is highlighted. Learners may ignore the fact that néng can also be used to make requests, or they may feel it safer to choose kéy̆ given the complexity of the usage of néng. Furthermore, while no explicit explanation is provided of the differences between néng and kěyl in requests in the textbook, an interview among the instructors revealed that none of them had explicitly explained the differences between the two modal verbs in making requests either.

Another relevant explanation concerns classroom teaching. As teaching in a classroom is a relatively formal activity, instructors may unconsciously choose the formal expression kěyı more often than the informal and common expression néng in the classroom. This has been confirmed in an interview among the instructors of the CFL learners. Instructors' more frequent use of kéy̌ in the classroom may, therefore, have had an impact on learners' overuse of this modal verb when making requests.

Another possible factor, as suggested by Faerch and Kasper (1989) and Hassall (2003), may relate to the inherently asymmetric role relationship between native and nonnative speakers, in which learners as nonnative speakers often feel that they hold the inferior position. Learners' perception of their status may have prompted them to select the more deferential and formal modal verb kéyı̌ instead of the more commonly used ability expression néng.

\section{Hints}

The present study showed that low proficiency learners chose hints considerably more often than either high proficiency learners or native speakers. This finding is consistent with previous studies. Trosborg (1995) reports that Danish learners of English at the lowest level choose hints the most often. Hassall (2003) also finds that low proficiency Australian learners of Indonesian employ hints more frequently than native speakers. Trosborg explains that the hints used by low proficiency learners are often pseudo-hints, which are qualitatively different from the hints produced by native speakers. While NSs use hints intentionally as a face-saving device, learners choose hints mainly because they are uncertain of the appropriate means and forms of realizing the impositive intent. This was confirmed in the present study. A closer inspection of the data indicates that hints mainly occurred in the $+\mathrm{P},+\mathrm{D}$ and $+\mathrm{R}$ situation, where a student asks a course coordinator to approve late addition of courses. Most of the low proficiency learners seemed to have difficulty in phrasing their request because of the Chinese word for 'approve/approval', although they had learned it. Due to pragmalinguistic shortcoming, learners tended to simply state their needs. The following is an example of hints by a low proficiency learner:

(12) 你好, 我 是 Xxx, 我 需要 学 CHIN2600。

nǐhăo, wǒ shì xxx, wǒ xūyào xué CHIN2600

[Hello, my name is xxx. I need to study CHIN2600.]

\section{Pragmalinguistic vs. Sociopragmatic Development}

The findings of the present study showed that as learners' language proficiency increased, their use of directness decreased, but their use of conventional indirectness increased. Moreover, high proficiency learners closely approximated native speakers in the underuse of the direct strategy Mood derivable and nonconventional indirectness. These may represent a development towards the target norm in learners' L2 pragmalinguistic competence. However, the findings revealed that while native speakers tended to vary their selection of request strategies according to social variables such as relative power, social distance and size of imposition, neither of the learner groups adjusted their selection of request strategies in accordance with the involved social variables. This may indicate that learners achieved little sociopragmatic development in making requests. Therefore, the present study suggests that Australian learners' acquisition of pragmalinguistic competence outperformed their sociopragmatic competence, lending support to the view of the precedence of pragmalinguistic development over sociopragmatic development (Barron, 2003; Li, 2018; Rose, 2000, 2009; Savić, 2015; Scarcella \& Brunak, 1981; Trosborg, 1995).

\section{CONCLUSION}


The present study compared requests made by Australian learners of Chinese with those by Chinese native speakers through a 6-situation DCT. Findings indicated that while both groups strongly favoured conventional indirectness, they preferred different strategy types. Moreover, this study provided some evidence of pragmalinguistic development but no evidence of sociopragmatic development, indicating that learners' pragmalinguistic development precedes their sociopragmatic development.

This study has several implications. Firstly, it contributes to studies of speech acts by learners of Chinese as a second/foreign language, which have been under-researched. Secondly, it sheds more light on research in interlanguage pragmatics and contributes to the current understanding of how L2 pragmatic competence develops. Moreover, this study has pedagogical implications for the learning and teaching of Chinese as a second/foreign language. The perception data in the present study show that learners' deviations from the target norm in the realizations of requests had a negative effect on native speakers' evaluations of their requests, which indicates that the deviations may cause pragmatic failure (Thomas, 1983) and communication breakdown. The present study points to a strong reason for the inclusion of pragmatics in teaching Chinese as a second/foreign language.

This study is subject to a few limitations. Firstly, the data were elicited through a DCT since the purpose of the present study was to assess learners' pragmatic knowledge of the linguistic means and forms learned. However, as discussed previously, the DCT data lack pragmatic features that are specific to oral interactive discourse. Secondly, this study is a cross-sectional study, which only provides indirect observation of L2 learners' pragmatic development. Thirdly, the sample size is relatively small. Only twenty participants were included in the native group and twenty in the CFL group which was further divided into low and high proficiency groups. This might influence the results of the study. Moreover, the fact that the number of male and female participants are not the same might also affect the results in some way. Therefore, the findings of the study should be interpreted only when all these limitations are taken into consideration.

The limitations of the present study highlight a number of research areas for consideration in future studies. Firstly, there is an obvious need for future research to investigate more speech acts in L2 Chinese given the paucity of existing studies in this area. Secondly, future studies could look at naturally occurring data or role-play data which allow examination of pragmatic features in natural and interactive conversation. Moreover, it would be desirable to adopt a multiple-method approach including retrospective interviews, which can help researchers have a better understanding of learners' pragmatic behaviour. Lastly, a longitudinal study, which provides more direct observation of learners' pragmatic development, could be conducted to meet the need for developmental research in L2 pragmatics.

\section{APPENDIX}

Imagine you have come across the following situations in your real life. Please write down what you would really say in such situations. You can write either in Chinese characters or pinyin or a mixture of characters and pinyin.

\section{Reference}

Suppose you are applying (申请 shēn qǔng) for a scholarship (奖学金, jiăng xué jīn ) to study in China. You need a reference letter (推荐信, tuī jiàn xìn). Dr Wendy Jiang has taught you Chinese for a year. You decide to ask her to write it for you. Now your Chinese class is over. What would you say to her?

\section{Notes}

Suppose you and Chris are both doing CHIN 3010/3020. You have learned Chinese in the same class for a year and often sit next to each other. You missed the Chinese class last week for some reason. Now you want to borrow Chris' lecture notes (笔记 bǐjì). What would you say to her/him?

\section{Pen}

Suppose you are attending a seminar. But you forgot to bring a pen. A Chinese student who sits next to you has some extra pens. You want to borrow it from him/her. What would you say?

\section{Handout}

Suppose you didn't attend Dr Wendy Jiang's lecture last week. Dr Jiang gives students handouts（练习 liànxí） each week. Now the class is over. You want to ask her to bring the handout you missed out to you next week. What would you say?

\section{Interview}

Suppose you have a Chinese assignment (作业 zuòyè) due next week. Each student is asked to interview (采访 căifang) a Chinese native speaker and ask 20 questions. Ling Zhang is your language partner. You want to ask him/her for help. Now you are calling him/her. What would you say?

\section{Course}

Suppose this semester you have to study four courses in order to graduate. You want to take CHIN 2600. But it's already Week 5. You have to ask the coordinator Dr Lucy Li for permission. You have never met her. Now you are knocking on her office door. What would you say to her? 


\section{REFERENCES}

[1] Achiba, M. (2003). Learning to request in a second language: Child interlanguage pragmatics. Clevedon: Multilingual Matters.

[2] Bardovi-Harlig, K. (2013). Developing L2 pragmatics. Language Learning, 63, 68-86.

[3] Bardovi-Harlig, K., \& Griffin, R. (2005). L2 pragmatic awareness: Evidence from the ESL classroom. System, 33, 401- 415

[4] Bardovi-Harlig, K., \& Hartford, B. S. (1993). Learning the rules of academic talk: A longitudinal study of pragmatic development. Studies in Second Language Acquisition, 15, 279-304.

[5] Barron, A. (2003). Acquisition in interlanguage pragmatics: Learning how to do things with words in a study abroad context. Amsterdam: John Benjamins.

[6] Beebe, L. M., \& Cummings, M. C. (1996). Natural speech act data versus written questionnaire data: How data collection method affects speech act performance. In S. M. Gass \& J. Neu (Eds.), Speech acts across cultures: Challenges to communication in a second language (pp. 65-86). Berlin: Mouton de Gruyter.

[7] Bella, S. (2012). Pragmatic development in a foreign language: A study of Greek FL requests. Journal of Pragmatics, 44 , 1917-1947.

[8] Blum-Kulka, S. (1982). Learning to say what you mean in a second language: A study of the speech act performance of learners of Hebrew as a second language. Applied Linguistics, 3(1), 29-59.

[9] Blum-Kulka, S., House, J., \& Kasper, G. (Eds.). (1989). Cross-cultural pragmatics: Request and apologies. Norwood: Ablex

[10] Brown, P., \& Levinson, S. (1987). Politeness: Some universals in language usage. Cambridge: Cambridge University Press.

[11] Byon, A. (2004). Sociopragmatic analysis of Korean requests: Pedagogical settings. Journal of Pragmatics, 36, $1673-1704$.

[12] Economidou-Kogetsidis, M. (2008). Internal and external mitigation in interlanguage request production: The case of Greek learners of English. Journal of Politeness Research, 4, 111-138.

[13] Economidou-Kogetsidis, M. (2010). Cross-cultural and situational variation in requesting behaviour: Perceptions of social situations and strategic usage of request patterns. Journal of Pragmatics, 42 (8), 2262-2281.

[14] Ellis, R. (1992). Learning to communicate in the classroom: A study of two language learners' requests. Studies in Second Language Acquisition, 14(1), 1-23.

[15] Faerch, C., \& Kasper, G. (1989). Internal and external modification in interlanguage request realization. In S. Blum-Kulka, J. House, \& G. Kasper (Eds.), Cross-cultural pragmatics: Request and apologies (pp. 221-247). Norwood: Ablex.

[16] Félix-Brasdefer, J. C. (2007). Pragmatic development in the Spanish as a FL classroom: a cross-sectional study of learner requests. Intercultural Pragmatics, 4, 253-286.

[17] Hassall, T. (2003). Requests by Australian learners of Indonesian. Journal of Pragmatics, 35, 1903-1928.

[18] Hinkel, E. (1997). Appropriateness of advice: DCT and multiple choice data. Applied Linguistics, 18, 1-26.

[19] Hong, W. (1997). Sociopragmatics in language teaching: With examples of Chinese requests". Journal of the Chinese Language Teachers Association, 32, 95 -107.

[20] Kasper, G. (1992). Pragmatic transfer. Second Language Research, 8(3), 203-231.

[21] Kasper, G., \& Dahl, M. (1991). Research methods in interlanguage pragmatics. Studies in Second Language Acquisition, 13, 215-247.

[22] Kasper, G., \& Rose, K. (2002). Pragmatic development in a second language. Oxford: Blackwell.

[23] Kasper, G., \& Schmidt, R. (1996). Developmental issues in interlanguage pragmatics. Studies in Second Language Acquisition, $18,149-169$.

[24] Lee-Wong, S. M. (1994). Imperatives in requests: Direct or impolite - Observations from Chinese. Pragmatics, 4(4), $491-515$.

[25] Li, S. (2012). The effects of input-based practice on pragmatic development of requests in L2 Chinese. Language Learning, 62, 403-438.

[26] Li, S. (2014). The effects of different levels of linguistic proficiency on the development of L2 Chinese request production during study abroad. System, 45, 103-116.

[27] Li, W. (2018). Pragmatic transfer and development: Evidence from EFL learners in China. Amsterdam: John Benjamins.

[28] Maeshiba, N., Yoshinaga, N., Kasper, G., \& Ross, S. (1996). Transfer and proficiency in interlanguage apologizing. In S. Gass $\&$ J. Neu (Eds.), Speech acts across cultures (pp. 155-187). Berlin: Mouton de Gruyter.

[29] Rose, K. (2000). An exploratory cross-sectional study of interlanguage pragmatic development. Studies in Second Language Acquisition, 22(1), 27-67.

[30] Rose, K. (2009). Interlanguage development in Hong Kong, phase 2. Journal of Pragmatics, 41, 2345-2364.

[31] Rue, Y., \& Zhang, G. (2008). Request strategies: A comparative study in Mandarin Chinese and Korean. Amsterdam: John Benjamins.

[32] Sasaki, M. (1998). Investigating EFL students' production of speech acts: A comparison of production questionnaires and role plays. Journal of Pragmatics, 30, 457-484.

[33] Savić, M. (2015). “Can I very please borrow it?”: Request development in young Norwegian EFL learners. Intercultural Pragmatics, 12(4), 443-480.

[34] Scarcella, R., \& Brunak, J. (1981). On speaking politely in a second language. International Journal of the Sociology of Language, 27, 59-75.

[35] Schmidt, R. (1983). Interaction, acculturation, and the acquisition of communicative competence: A case study of one adult. In N. Wolfson \& E. Judd (Eds.), Sociolinguistics and language acquisition (pp. 137-174). New York: Newbury House.

[36] Searle, J. (1969). Speech acts: An essay in the philosophy of language. Cambridge: Cambridge University Press.

[37] Taguchi, N. (2015). Pragmatics in Chinese as a second/foreign language. Studies in Chinese Learning and Teaching, 1(1): 3-17.

[38] Thomas, J. (1983). Cross-cultural pragmatic failure. Applied Linguistics, 4(2), 91-112.

[39] Trosborg, A. (1995). Interlanguage pragmatics: Requests, complaints, and apologies. Berlin: Mouton de Gruyter.

[40] Wang, V. X. (2011). Making requests by Chinese EFL learners. Amsterdam: John Benjamins.

[41] Wen, X. (2014). Pragmatic development: An exploratory study of requests by learners of Chinese. In Z. Han (Ed.), Studies in 
Second language acquisition of Chinese (pp. 30-56). Bristol/New York: Multilingual Matters.

[42] Wierzbicka, A. (1985). Different cultures, different languages, different speech acts. Journal of Pragmatics, 9, 145-178.

[43] Woodfield, H. (2012). I think maybe I want to lend the notes from you: Development of request modification in graduate learners. In M. Economidou-Kogetsidis \& H. Woodfield (Eds.), Interlanguage Request Modification (pp. 9-49). Amsterdam: John Benjamins.

[44] Woodfield, H. \& Economidou-kogetsidis, M. (2010). 'I just need more time': A study of native and non-native students' requests to faculty for an extension. Multilingua, 29, 77-118.

[45] Wu, Z. (2015). Contemporary Chinese (Revised Edition) Volumes 1, 2 \& 3 Textbooks. Beijing: Sinolingua.

[46] Yu, M. C. (1999). Universalistic and culture-specific perspectives on variation in the acquisition of pragmatic competence in a second language. Pragmatics, 9(2), 281-312.

[47] Zhang, D., \& Yu, Y. (2008). Context of learning and requesting in Chinese as a second language: An exploratory study of students learning Chinese in study abroad and at home contexts. Journal of Chinese Language Teachers' Association, 43, 73-92.

[48] Zhang, Y. (1995). Strategies in Chinese requesting. In G. Kasper (Ed.), Pragmatics of Chinese as native and target language (pp. 23-68). Honolulu, HI: University of Hawaii Press.

Wei $\mathbf{L i}$ is currently a Chinese language instructor in the Chinese program in the School of Languages and Cultures at the University of Queensland. Her research interests include pragmatics, interlanguage and intercultural pragmatics, teaching Chinese/English as a second/foreign language, technology enhanced language learning, and translation studies.

Wenying Jiang is a lecturer in Chinese in the Chinese program in the School of Languages and Cultures at the University of Queensland. Her research interests include second language acquisition of Chinese, Chinese pedagogy, technology enhanced language learning and intercultural communication. 